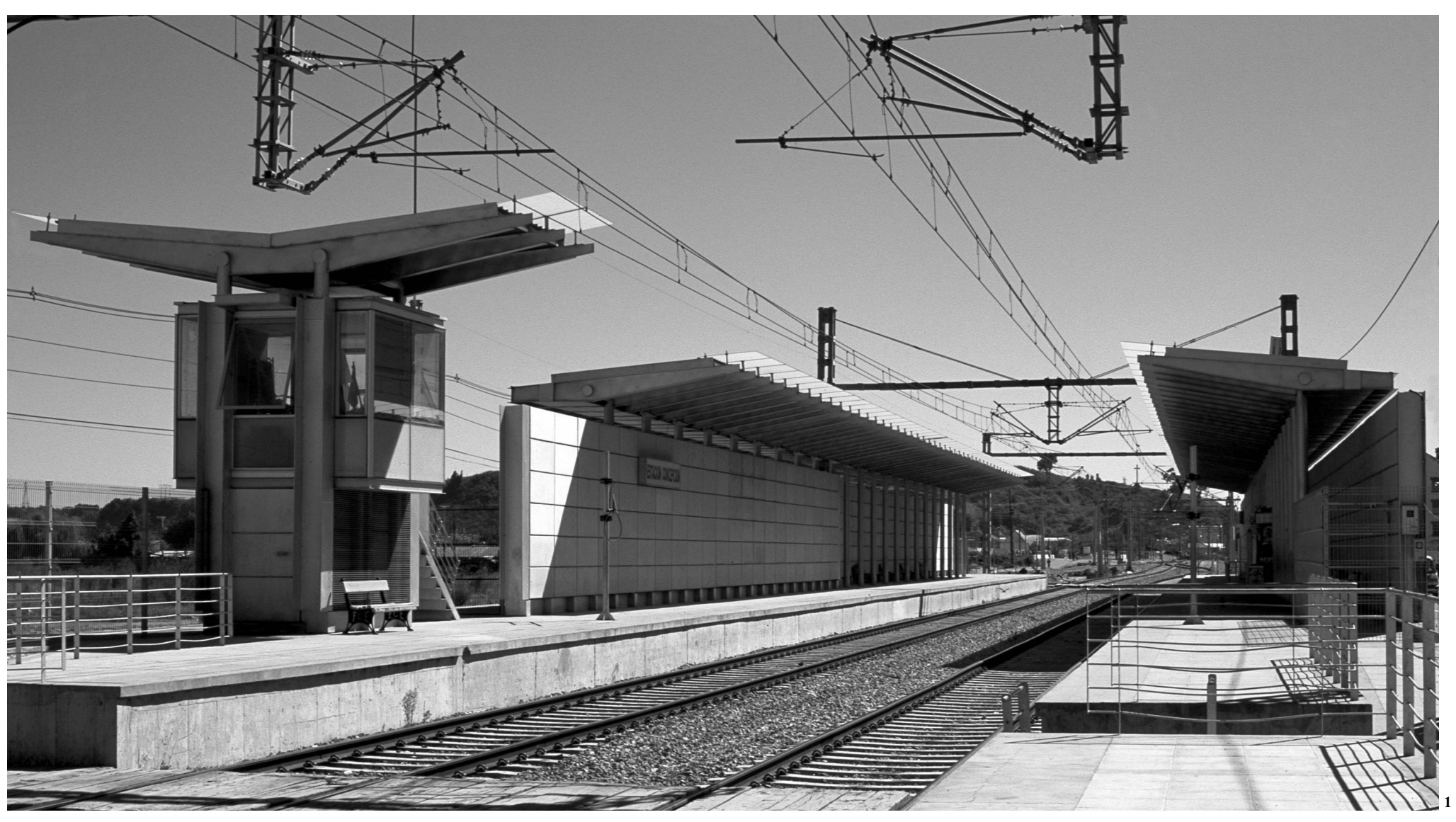

Cristián Fernández E.

\title{
Estación Bio Tren
}

Por un lado, las iniciativas gubernamentales para reactivar la actividad ferroviaria; por otra parte, una ciudad sometida a un plan de renovación. Esta propuesta para una estación de trenes en Concepción es una de las primeras señales en esta dirección, materializada en una estructura desmontable -para su posible traslado-, una lógica constructiva de elementos prefabricados y una imagen corporativa expresiva de las características del mundo tecnológico y repetitivo de los ferrocarriles.

Palabras clave: Arquitectura- Concepción, estación de ferrocarril.

On the one hand, the government's attempt to revitalize the railway transportation system; on the other hand, a city that is undergoing a process of urban renewal. This proposal for a railway station in Concepción is one of the first signs in this direction. It consists of a detachable structure (so it can be transported elsewhere), constructed with prefabricated elements and a corporative image that expresses the nature of the technological and repetitive world of the railway system. Keywords: Architecture- Concepción, railway station.
Luego de un largo período en que la inversión pública en infraestructura de transporte se destinó principalmente a redes viales, privilegiando el uso del automóvil y los buses interurbanos, volvemos a encontrarnos con iniciativas que pretenden diversificar los modos en que nos movemos por el territorio. Al igual que el nuevo tren a Chillán o la modernización del ferrocarril ValparaísoViña del Mar, la nueva estación para el Bio Tren de Concepción forma parte de un conjunto de acciones que por un lado reincorporan al ferrocarril como medio de transporte viable, al tiempo que renuevan la relación de estas estructuras con la ciudad.

Este encargo tuvo al menos tres requisitos:

- Diseñar un edificio, que albergara toda la complejidad técnica y funcional propia de una estación de Metro tren.

- Que su diseño y materialidad fuesen soportes de una imagen corporativa para las estaciones de Metro tren.

- Diseñar un sistema constructivo que permitiera una rápida instalación y eventualmente el traslado futuro.

La estación se estructura sobre la base de la repetición de pilares cilíndricos metálicos galvanizados, los cuales son revestidos al interior por paneles prefabricados de hormigón armado y al exterior por unas parrillas metálicas electroforjadas y galvanizadas, montadas en sentido horizontal.

Estos extensos muros perimetrales, huecos y semitransparentes, que contienen el espacio de la estación, están construidos como mecano, en base a pernos, anclajes y remaches, y se ven a pesar de su materialidad de hormigón y fierro, como suspendidos en el aire, ya que sus apoyos estructurales quedan postergados en el alma del muro.

Los diferentes elementos constructivos se relacionan de manera independiente o tangente unos con otros, buscando generar una gran tensión horizontal, y un sentido repetitivo, característico del mundo ferroviario.

Las cubiertas que cubren los andenes, construidas en fierro, paneles de aluminio y cristal templado, tampoco tocan los muros, pues descansan en los pilares cilíndricos que van directamente al suelo por el interior de los muros.

A la calle se ofrece una extensa fachada limpia, constituida por pocos elementos, que representa de modo casi literal lo que el edificio alberga en su interior. ARQ 
1 Caseta de control y andenes

2 Interior andenes

3 Acceso
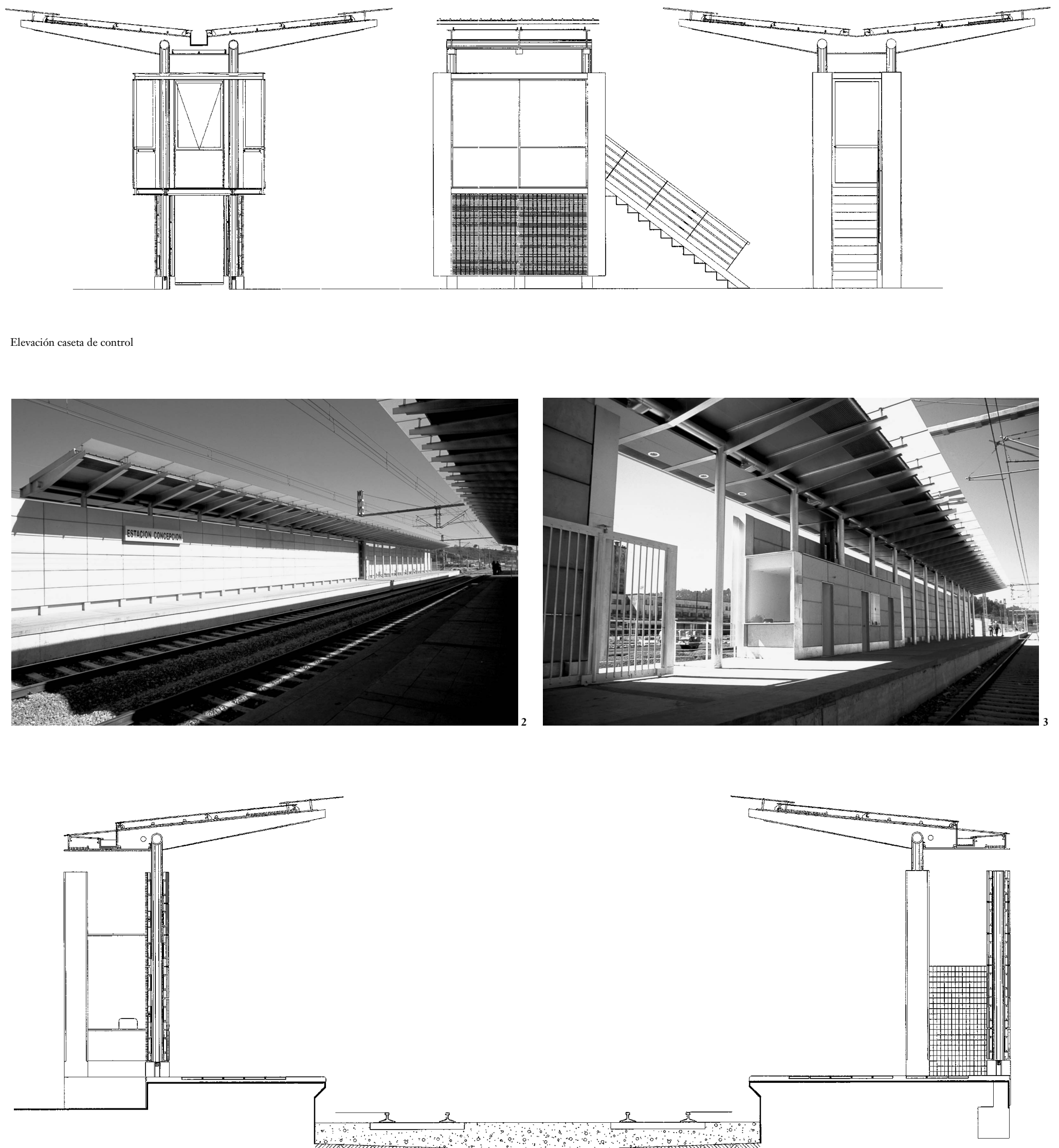

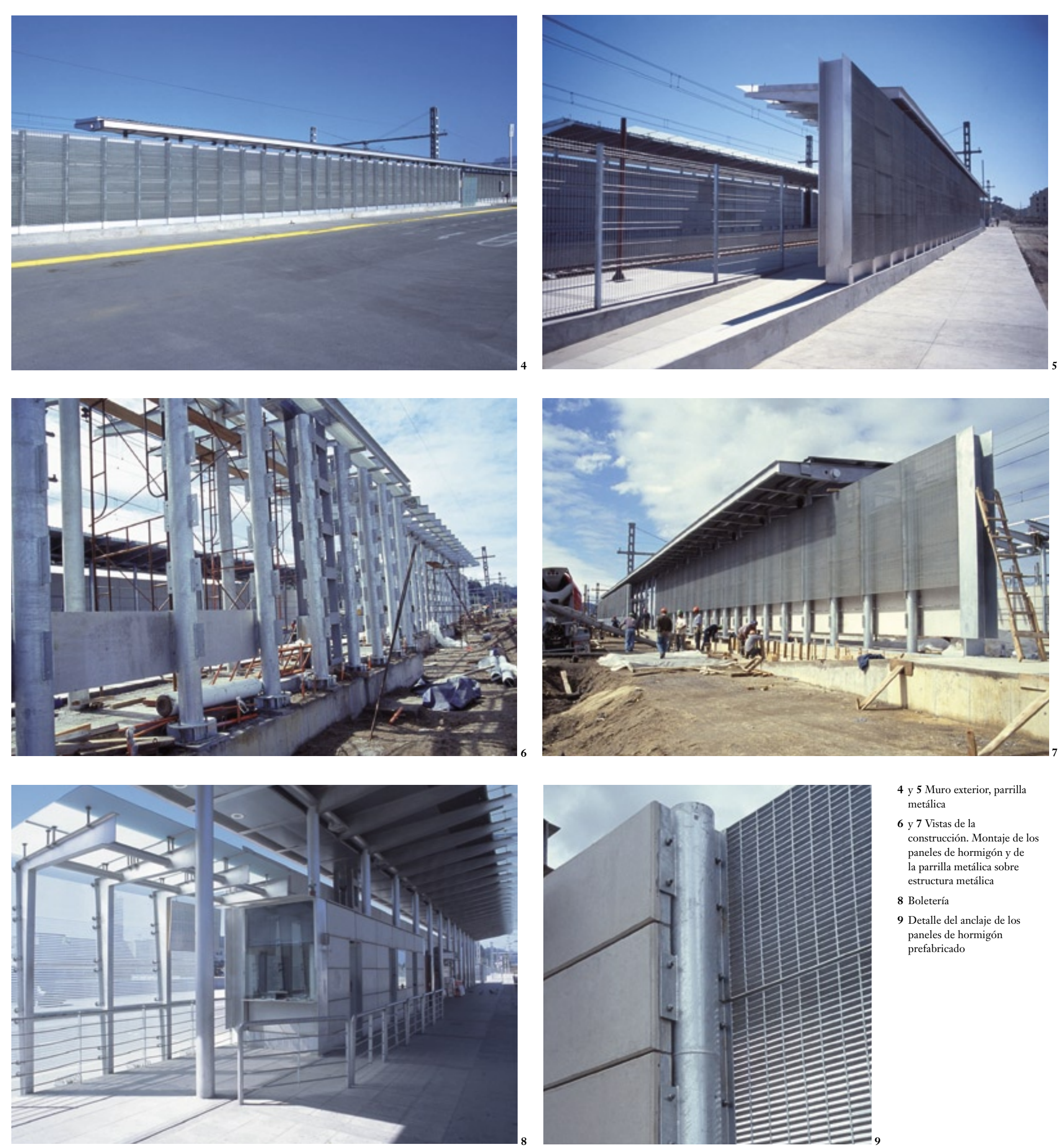

4 y 5 Muro exterior, parrilla

6 y 7 Vistas de la

construcción. Montaje de los paneles de hormigón y de la parrilla metálica sobre estructura metálica 8 Boletería

9 Detalle del anclaje de los paneles de hormigón prefabricado 


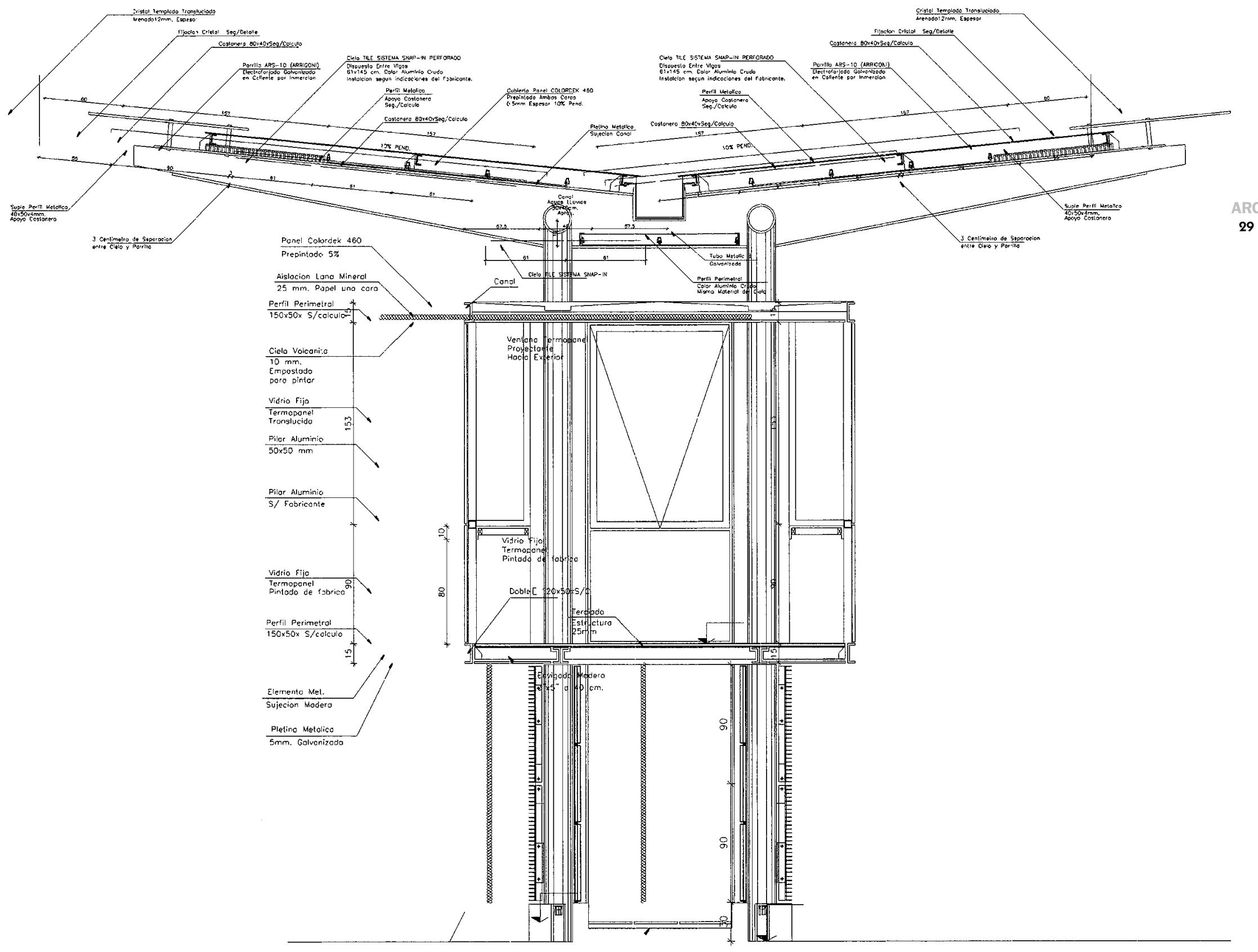

Caseta de control, escantillón
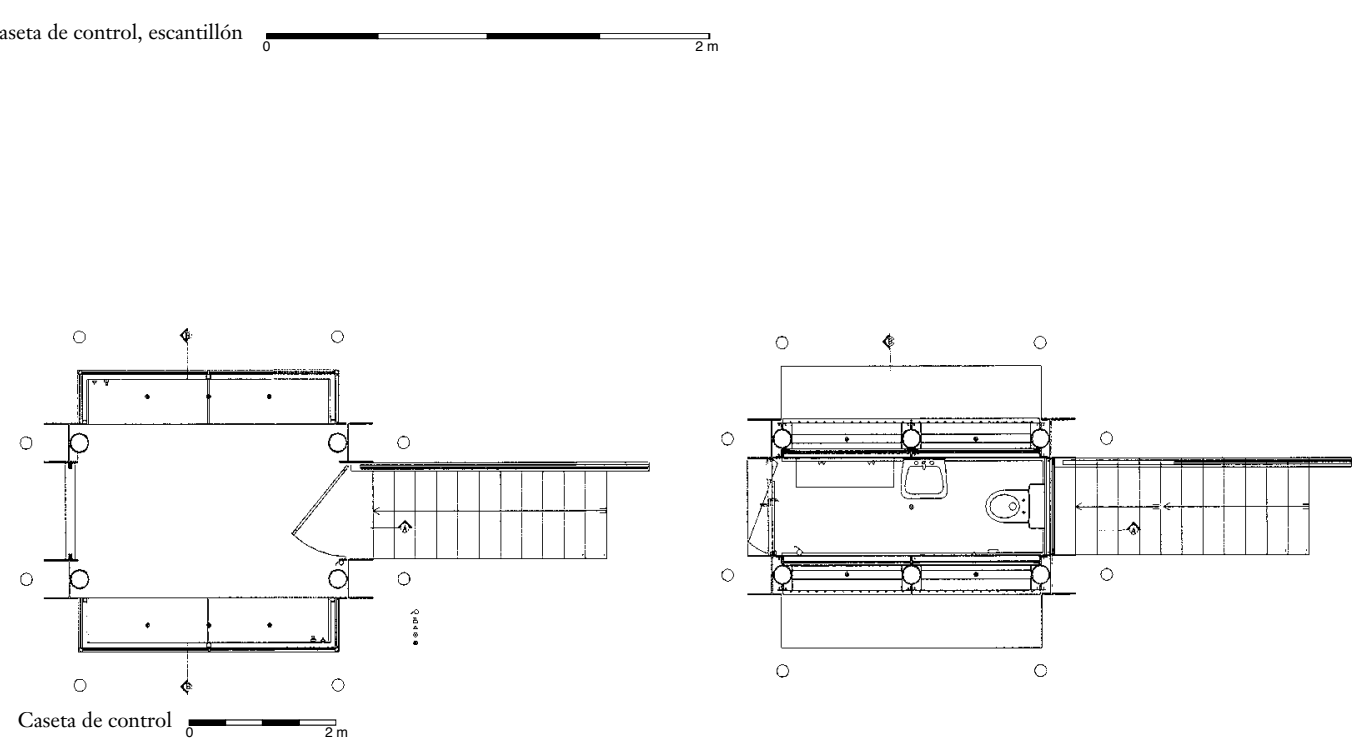

Estación Bio Tren

Arquitectos Cristián Fernández E. y Asociados

Colaboradores Antonio Aguilera, Marcelo Fernández, Verónica Montecinos

Ubicación Terrenos EFE, Costanera Norte, Concepción

Mandante Inmobiliaria Nueva Vía S.A. (INVIA)

Cálculo estructural Eduardo Spoerer y Antonio Medina

Construcción Icil Icafal Ltda.

Asesores Técnicos Cristián Beseler y Jaime Contreras

Inspector Técnico José Guillermo Iglesias

Superficie cubierta $720 \mathrm{~m}^{2}$ aprox.

Año proyecto 1999, construcción 2000

Fotografía Guy St.-Clair 